Journal of Dental Education, Vol 67, No. 6, 2003, pp.654-660.

ISSN: (Print: 0022-0337 ) (Online: 1930-7837)

http://www.jdentaled.org/.

http://www.jdentaled.org/cgi/reprint/67/6/654

(C) American Association of Dental Schools 


\title{
The Impact of Gender on High-Stakes Dental Evaluations
}

\author{
Henry W. Fields, D.D.S., M.S., M.S.D.; Anne M. Fields, M.A., Ph.D.; \\ F. Michael Beck, D.D.S., Ph.D.
}

Abstract: The purpose of this study was to determine whether gender affects high-stakes test performance among dental students. Our sample consisted of 128 women and 323 men from six consecutive dental classes for which we recorded AADSAS overall and science predental GPAs; Dental Admission Test (DAT) scores; National Board Dental Examination (NBDE) I and II scores and pass/fail status; North East Regional Board of Dental Examiners (NERB) pass/fail status; and cumulative GPAs following the spring quarter of year two and summer quarter of year four of dental school. DAT scores, when controlled for previous academic performance, revealed that men significantly outperformed women in all areas except reading comprehension and biology, where the women's scores significantly exceeded the men's and were comparable, respectively. NBDE I results favored men and approached significance ( $\mathrm{p}=0.066$ ), while for Part II men significantly outscored women. NBDE I and II and NERB pass rates showed no significant differences. These board results were also controlled for previous academic performance. Although we found that differences existed between genders, which appear to be the ramification of the classic high-stakes dilemma (women do as well as men in the classroom and on course-related tests, but less well on gatekeeper board exams), the context mitigates their operational effects. DAT differences are likely reduced by most admissions processes, but may be problematic when selected predictive algorithms are used. Practically, the NBDE I and II results are unlikely to meaningfully influence women's academic progress in dental school or postgraduate education admissions due to their magnitude and timing.

Dr. Henry Fields is Professor, Section of Orthodontics, College of Dentistry; Dr. Anne Fields is Assistant Professor, Education, Psychology, and Social Work Library; and Dr. Beck is Associate Professor, Section of Oral Biology, College of Dentistry, all at Ohio State University. Direct correspondence to Dr. Henry W. Fields, Ohio State University College of Dentistry, 4088 Postle Hall, 305 West $12^{\text {th }}$ Ave., P.O. Box 182357, Columbus, OH 43218-2357; 614-292-1120 phone; 614-688-3077 fax; fields.31@osu.edu.

Key words: dental education, dental students, educational measurement, credentialing, certification, dental licensure, women dentists, achievement, aptitude tests

Submitted for publication 1/21/03; accepted 4/8/03

I $\mathrm{n}$ many professions, including the health sciences, multiple high-stakes testing events can impact the student evaluation process during the formative years. These events include preadmissions testing such as the Medical College Admissions Test (MCAT), Law School Admissions Test (LSAT), and Dental Admission Test (DAT) and national certifying examinations like the United States Medical Licensing Examination (USMLE Step 1, 2, and 3), National Board Dental Examination (NBDE Parts I and II), and National Board of Osteopathic Medical Examiners (NBOME Level 1, 2, and 3). In dentistry, there are additional regional clinical licensure examinations, for example, the Western Regional Examining Board (WREB), Central Regional Dental Testing Service (CRDTS), Southern Regional Testing Agency (SRTA), and North East Regional Board of Dental Examiners (NERB), as well as numerous single state boards.
Researchers have long acknowledged a gender gap in high-stakes testing performance that many consider a truism: "Males turn out to be better test takers and females turn out to be better course takers." "Although some have disagreed about whether the gap is decreasing, ${ }^{2-4}$ the gap remains, and highstakes examinations fail to accurately reflect or predict women's classroom performance.

This discrepancy between high-stakes testing results and other preadmissions criteria remains noticeable at higher educational levels, including dental school admissions. Results of the April and August 2000, 2001, and 2002 MCAT show women scoring lower than men on the verbal reasoning, physical sciences, and biological sciences portions of the test. ${ }^{5}$ Results of the GRE General Test from 1988 to 1998 show that men outscored women in all ethnic and racial groups for the verbal, quantitative, and analytical portions of the test. ${ }^{6}$ 
Graham $^{7}$ found no consistent differences between men and women in DAT scores in 1973 or 1974, but only 8 percent of students applying at that time were women. A study published in 1986 by Pot$\operatorname{ter}^{8}$ of six classes at Indiana University, however, showed women applicants had a higher mean score in college nonscience GPA, while men applicants had a higher mean score in three-dimensional perceptual ability on the DAT. Recent data ${ }^{9}$ demonstrate gender differences for the DAT, although these studies have not controlled for comparable academic ability or performance.

Whereas several studies have examined different aspects of gender in dental education, ${ }^{10-13}$ few have assessed gender's effects on post-admission high-stakes test performance in dentistry. In one, Casada, Cailleteau, and Seals ${ }^{14}$ found no significant relationship between gender and passage of state and regional boards.

Studies in other professions suggest that differences appear to continue in the post-admission years. A survey of the literature by Weinberg and Rooney ${ }^{15}$ found men generally outscoring women on USMLE Part I, but those differences had disappeared - except within certain specialty-related portions-by USMLE Part II. Case, Becker, and Swanson ${ }^{16}$ found similar results twenty years later. Looking at scores for the NBOME Level 1, 2, and 3, Shen ${ }^{17}$ found similar results. Women performed less well than men on Level 1, performed similarly on Level 2, and performed better on Level 3. Speculating on possible causes for improving performances, Case, Becker, amd Swanson ${ }^{16}$ reported:

[Some researchers] have suggested that men and women adapt differently to stresses in medical schools (including sexism) in ways that might be to the disadvantage of women in the early years but to their advantage later on. ... Others have noted that women tend to perform better in areas related to specialties attracting large numbers of women [for instance, pediatrics and obstetrics], and these specialties may place less emphasis on strong Part I performance. . . . Finally, it is possible that, on average, women have a weaker background in science at the time of matriculation, but "catch up" as a result of medical school training. Several researchers have noted that differences in Part I performance is larger in disciplines traditionally taught in the first year.
Shen ${ }^{17}$ suggested, on the other hand, "that women and men have different growth patterns and that women grow relatively faster than men within the current medical education system."

Despite these gains, differences exist in 197382 scores between men and women on the American Board of Internal Medicine Certifying Examination. ${ }^{18}$ Although women's scores improved compared to the men's, women's scores still remained lower regardless of their performance in their residency programs. Studies by Klein ${ }^{19}$ and Ryman ${ }^{20}$ both revealed that, unlike men, women law students performed less well on their bar examinations than might have been predicted by their performance in law school.

A number of possible reasons have been suggested for the gender gap on high-stakes tests, many relating to women's traditionally lower sense of selfesteem when compared to men. ${ }^{21}$ These factors include stereotype threat, differential speeds, aversion to risk taking, test bias, fear of success, test anxiety, and certain other personal characteristics. ${ }^{22}$

Because dentistry has several levels of highstakes testing, because a growing number of students entering this system are women, and because of the equivocal results of earlier studies cited here, it appears more important than ever to determine if a highstakes gender gap exists in the evaluation processes used in dental education. Performance on critical evaluation instruments not only can adversely dictate entrance to dental school by qualified applicants, but can be used as a winnowing device for licensure and specialty education, ultimately influencing the supply of qualified dentists. If similarly trained and academically performing women do not demonstrate equal success on traditional measurement instruments, an undesirable shaping of the overall profession potentially could occur both on a larger scale and within its disciplines. The purpose of this study was to determine whether gender significantly affects high-stakes test performance among dental students at several points in the educational process.

\section{Materials and Methods}

All undergraduate students must submit academic performance information in order to be considered for admission to dental schools. This information is collected and transmitted to the dental college admissions groups by the application process of the Associated American Dental Schools 
Application Service (AADSAS) overseen by the American Dental Education Association (ADEA) and includes standardized calculations of overall and science predental school GPAs. The students also complete the DAT as an application requirement, which the ADEA testing service also reports to the dental colleges. These data formed the basis for the preadmissions information gathered for the sample of students involved in this project. Cumulative GPAs were computed for each dental school grading period. The students involved in this investigation completed the NBDE I and NBDE II following the spring quarter of year two and during autumn quarter of year four, respectively. A majority of the students also attempted the NERB examination during the final quarter in dental school. All results noted above were reported to the college and held on file, with the exception of some individual clinical examination results. The above-cited repository of data existed in the Offices of Admissions and Academic Affairs for the graduating classes of 1996-2001. Table 1 demonstrates the time points, comparisons, control variables, and sample sizes. This study was approved by the Behavioral and Social Sciences Human Subjects IRB. The approval included a waiver of written consent.

The comparisons varied among the several high-stakes events. For the DAT, score comparisons were made because that is the data used by admissions committees. For NBDE I and II, score and pass rate comparisons were made because student scores are used as a postdoctoral admissions factor and students must pass the national boards at a number of institutions to complete graduation requirements or advance in standing. Passing a regional or state board is also required for licensure in most states. Passing was the only comparison for the NERB because, operationally, that is the only outcome of consequence.

With a nondirectional alpha risk of 0.05 , a power of 90 percent, and a female/male split of 30 percent/ 70 percent, a sample size of $108 / 252$ subjects (female/ male) was required to detect a difference of \pm 1.75 points in all components of the Dental Admission Test and Parts I and II of the National Dental Board Examination. For the same alpha risk and a power of 88 percent, a sample size of 51/117 subjects was required to detect a difference of \pm 25 percent in pass rates on the North East Regional Board.

Data from this study were analyzed in the following manner. DAT scores were assessed using an analysis of covariance with gender as the independent variable and cumulative, undergraduate science GPA as a covariate. A similar model was used to evaluate scores on NBDE Parts I and II. In this case, the covariates were cumulative dental school GPA as of spring quarter of the second year (for Part I) and summer quarter of the fourth year (for Part II). Logistic regression was used to model passing performance on the NERB examination. Independent variables included gender and final cumulative dental school GPA.

\section{Results}

The raw data (Table 2) indicated that for matriculating students the measures of academic performance were equal for males and females when

Table 1. High-stakes evaluations for dental professionals

\begin{tabular}{lcccc} 
Time Point & $\begin{array}{c}\text { High-Stakes Data } \\
\text { for Comparison }\end{array}$ & Control Variables & Women & Men \\
\hline Preadmission & DAT & Baccalaureate Science GPA & 128 & 323 \\
Credentialing & NBDE I & Cumulative GPA Spring Yr 02 & 117 & 300 \\
& NBDE II & Cumulative GPA Summer Yr 04 & 108 & 289 \\
Licensure & NERB & Final Cumulative GPA & 67 & 216
\end{tabular}

Table 2. Mean predental performance by gender

\begin{tabular}{|c|c|c|c|c|c|c|c|c|c|c|c|c|}
\hline Measure & $\mathrm{N}$ & $\begin{array}{l}\text { Adjusted } \\
\text { Mean* }\end{array}$ & $\begin{array}{c}\text { FEMALE } \\
\text { Adjusted } \\
\text { SE* }\end{array}$ & $\begin{array}{c}\text { Raw } \\
\text { Mean }\end{array}$ & $\begin{array}{c}\text { Raw } \\
\text { SE }\end{array}$ & $\mathrm{N}$ & $\begin{array}{c}\text { Adjusted } \\
\text { Mean* }\end{array}$ & $\begin{array}{c}\text { MALE } \\
\text { Adjusted } \\
\text { SE* }\end{array}$ & $\begin{array}{l}\text { Raw } \\
\text { Mean }\end{array}$ & $\begin{array}{r}\text { Raw } \\
\text { SE }\end{array}$ & $\mathrm{p}$ & $\begin{array}{c}\text { Delta percent } \\
(\text { Base }=\sigma)\end{array}$ \\
\hline \multicolumn{13}{|c|}{$\begin{array}{l}\text { Predental } \\
\text { AADSAS GPA }\end{array}$} \\
\hline Overall & 128 & na & na & 3.08 & 0.0418 & 323 & na & na & 3.09 & 0.024 & 0.9152 & -0.32 \\
\hline Science & 128 & na & na & 3.21 & 0.0329 & 323 & na & na & 3.18 & 0.021 & 0.4411 & 0.94 \\
\hline
\end{tabular}




\begin{tabular}{|c|c|c|c|c|c|c|c|c|c|c|c|c|}
\hline Measure & $\mathrm{N}$ & $\begin{array}{c}\text { Adjusted } \\
\text { Mean* }\end{array}$ & $\begin{array}{c}\text { FEMALE } \\
\text { Adjusted } \\
\text { SE* }\end{array}$ & $\begin{array}{l}\text { Raw } \\
\text { Mean }\end{array}$ & $\begin{array}{r}\text { Raw } \\
\text { SE }\end{array}$ & $\mathrm{N}$ & $\begin{array}{c}\text { Adjusted } \\
\text { Mean* }\end{array}$ & $\begin{array}{c}\text { MALE } \\
\text { Adjusted } \\
\text { SE* }^{*}\end{array}$ & $\begin{array}{l}\text { Raw } \\
\text { Mean }\end{array}$ & $\begin{array}{r}\text { Raw } \\
\text { SE }\end{array}$ & $\mathrm{p}$ & $\begin{array}{c}\text { Delta percent } \\
\left(\text { Base }=\sigma^{\prime}\right)\end{array}$ \\
\hline \multicolumn{13}{|l|}{ DAT Scores } \\
\hline ACAD & 128 & 17.06 & 0.16 & 17.05 & 0.16 & 323 & 17.64 & 0.10 & 17.64 & 0.11 & 0.0019 & -3.29 \\
\hline PAT & 128 & 15.96 & 0.21 & 15.95 & 0.19 & 323 & 17.33 & 0.13 & 17.33 & 0.14 & 0.0301 & -7.91 \\
\hline QR & 128 & 15.97 & 0.25 & 15.97 & 0.22 & 323 & 17.36 & 0.16 & 17.36 & 0.17 & $<0.0001$ & -8.01 \\
\hline $\mathrm{RC}$ & 128 & 19.26 & 0.21 & 19.26 & 0.21 & 323 & 18.65 & 0.13 & 18.65 & 0.13 & 0.0163 & 3.27 \\
\hline $\mathrm{BIO}$ & 128 & 16.63 & 0.19 & 16.63 & 0.18 & 323 & 17.02 & 0.12 & 17.03 & 0.13 & 0.0748 & -2.29 \\
\hline INO & 128 & 17.10 & 0.23 & 17.09 & 0.24 & 323 & 17.94 & 0.15 & 17.94 & 0.16 & 0.0027 & -4.68 \\
\hline ORG & 128 & 16.18 & 0.26 & 16.17 & 0.25 & 323 & 17.27 & 0.17 & 17.28 & 0.18 & 0.0005 & -6.31 \\
\hline TOTSCI & 128 & 16.55 & 0.17 & 16.55 & 0.17 & 323 & 17.26 & 0.11 & 17.27 & 0.12 & 0.0005 & -4.11 \\
\hline
\end{tabular}

*least-squares means adjusted for GPA

Table 4. Mean national board scores by gender

\begin{tabular}{|c|c|c|c|c|c|c|c|c|c|c|c|c|}
\hline Measure & $\mathrm{N}$ & $\begin{array}{l}\text { Adjusted } \\
\text { Mean* }\end{array}$ & $\begin{array}{c}\text { FEMALE } \\
\text { Adjusted } \\
\text { SE* }\end{array}$ & $\begin{array}{l}\text { Raw } \\
\text { Mean }\end{array}$ & $\begin{array}{r}\text { Raw } \\
\text { SE }\end{array}$ & $\mathrm{N}$ & $\begin{array}{l}\text { Adjusted } \\
\text { Mean* }\end{array}$ & $\begin{array}{c}\text { MALE } \\
\text { Adjusted } \\
\text { SE* }\end{array}$ & $\begin{array}{l}\text { Raw } \\
\text { Mean }\end{array}$ & $\begin{array}{r}\text { Raw } \\
\text { SE }\end{array}$ & $p$ & $\begin{array}{c}\text { Delta percent } \\
(\text { Base }=\sigma)\end{array}$ \\
\hline Part I & 117 & 83.91 & 0.30 & 84.05 & 0.45 & 300 & 84.55 & 0.18 & 84.50 & 0.28 & 0.0663 & -0.76 \\
\hline Part II & 108 & 80.61 & 0.31 & 81.06 & 0.46 & 289 & 81.46 & 0.19 & 81.29 & 0.28 & 0.0213 & -1.04 \\
\hline
\end{tabular}

*least-squares means adjusted for GPA

Table 5. Mean percentage passing rate for national boards and NERB by gender

\begin{tabular}{|c|c|c|c|c|c|c|c|c|c|}
\hline \multirow{2}{*}{ Measure } & \multicolumn{2}{|c|}{ FEMALE } & \multicolumn{2}{|c|}{ MALE } & \multirow[b]{2}{*}{$\begin{array}{c}\text { Delta Percent } \\
(\text { Base }=\sigma)\end{array}$} & \multirow{2}{*}{$\begin{array}{c}\text { Adjusted } \\
\text { Odds Ratio* } \\
\left(\text { Base }=\sigma^{*}\right)\end{array}$} & \multirow[b]{2}{*}{$\begin{array}{l}\text { Lower } \\
\text { Bound }\end{array}$} & \multirow[b]{2}{*}{$\begin{array}{l}\text { Upper } \\
\text { Bound }\end{array}$} & \multirow{2}{*}{$\mathrm{p}$} \\
\hline & Number & Percent & Number & Percent & & & & & \\
\hline Part I & 109 & 93.16 & 283 & 94.33 & -1.2403 & 0.954 & 0.377 & 2.621 & 0.9225 \\
\hline Part II & 100 & 92.59 & 278 & 96.19 & -3.7426 & 0.379 & 0.135 & 1.089 & 0.0647 \\
\hline NERB & 38 & 56.72 & 142 & 65.74 & -13.7207 & 0.631 & 0.356 & 1.121 & 0.1140 \\
\hline
\end{tabular}

*adjusted for GPA

considering the two dimensions of overall and science GPAs calculated by the AADSAS process.

The DAT component aptitude scores, both raw and adjusted, for predental academic performance are shown in Table 3. The academic average (ACAD) included all components of the DAT except the Perceptual (PAT) portion. This score plus the scores for PAT, quantitative reasoning $(\mathrm{QR})$, inorganic chemistry (INO), organic chemistry (ORG), and the total science score (TOTSCI), which included biology (BIO), INO, and ORG all demonstrated significant differences favoring men. The mean percentage differences for these scores varied from 2.29 to 8.01 percent. Reading comprehension scores significantly favored women and demonstrated a 3.27 percent difference. There were no significant differences in the scores for biology.

The national board scores, NBDE I and II, again adjusted for the most concurrent cumulative academic performance, were contrasting between genders. For NBDE I, differences favoring men ap- proached significance $(\mathrm{p}=0.066)$, while men significantly outscored women on NBDE II (Table 4). When the pass rates for NBDE I and II and NERB were considered and adjusted for academic performance, the findings were different from the test score results (Table 5). There were no significant differences for pass rate on any of these examinations. Notably, pass rates for men and women on the NBDE II only approach significance $(0.065)$ even though the raw scores on this examination were significantly different.

\section{Discussion}

The focus of this research was not whether men or women performed better at critical guideposts in the dental admissions and education process, but whether equally prepared students of each gender performed equally on these high-stakes examinations. In other words, given equal students, did genderrelated performance differences occur on high stakes 
examinations? Certainly at this institution, male and female students appeared equally prepared based on predental academic performance demonstrated by the predental overall and science GPAs compiled by AADSAS

In the first high-stakes encounter in the dental education pathway - the DAT - men significantly outperformed equally prepared women in all areas except reading comprehension and biology, where the women's scores significantly exceeded the men's and were comparable, respectively. There are a number of possible explanations for these gender differences. First, some have noted that there are "wellestablished" gender differences for cognitive activities. Maccoby and Jacklin ${ }^{23}$ concluded that men had better abilities in quantitative and visual-spatial areas, while women exceeded in verbal ability. The conclusion regarding the "well-established" gender differences in cognitive abilities was challenged by Hyde, ${ }^{24}$ who objected to the implication that the differences were large. Hyde's meta-analysis demonstrated that the differences not only were small, but that gender explained less than 5 percent, at most, of the cognitive difference. In our experimental design, these types of differences, regardless of magnitude, should have been eliminated by controlling for previously demonstrated academic ability.

A group of different studies provide perspective on the NBDE I and II results that we obtained. Shen, ${ }^{17}$ for example, found that differences in performance on NBOME Parts I, II, and III demonstrated that women performed less well on Part I, equally on Part II, and better on Part III. This trend held up for multiple schools and was not dependent on the school's male/female student ratios. Shen attributed this longitudinal change in performance to women's faster growth in medical education compared to men's.

Case, Becker, and Swanson ${ }^{16}$ found that the raw scores on NBME Parts I and II generally favored men on Part I and women on Part II. When the investigators controlled for prematriculation measures such as science GPA and MCAT scores, gender differences favoring men on Part I were reduced and the gender differences favoring women were increased. In this study after making the adjustments noted above, male students with identical prematriculation backgrounds had NBME scores 0.2 sd greater than women in all areas except behavioral sciences where women outscored men by $0.1 \mathrm{sd}$. The same trends were evident when controlling for prematriculation variables in Part II. When prematriculation and Part I scores were controlled, women outperformed men by 0.05 to $0.40 \mathrm{sd}$. These trends toward better performance from NBDE Part I to Part II when controlling for academic performance, however, did not hold true for our data where men outperformed women on Part II. The magnitude of the differences were similar and ranged from 0.2 to 0.6 sd for the DAT, NBDE I, and NBDE II.

Other possible explanations for gender differences have been attributed to stereotype threat, which is essentially a self-fulfilling prophecy of the stereotypically poorer performance that is expected of women. Concisely, "consideration of gender issues in tests and assessment is based most fundamentally on the existence and effects of two related yet distinct sociocultural processes, that of genderrelated socialization and stereotyping, first, and, second, that of sexism, not only in society itself but in counseling and testing." ${ }^{21}$ Speed also has been implicated because women's tendency toward deliberate and thorough problem-solving is penalized in timed multiple-choice examinations, which are typically constructed so that students must answer questions every forty-five to sixty seconds in order to complete the test. Guessing can penalize women because they are less likely to take risks and generally undervalue their knowledge. Some subject matter also favors males over females. ${ }^{22}$

These interpretations of the mechanisms at play in high-stakes testing were confirmed in part by Sackett, Schmitt, Ellingson, and Kabin. ${ }^{25}$ They suggested that biasing could be reduced by reducing cultural bias in questions, minimizing reading and writing skills by providing tests using video technology, and motivating students. Conversely, data from female and male dental students showed that female dental students had a more accurate estimation of their knowledge than did male dental students, so they actually did not undervalue their knowledge. ${ }^{12}$

A related and possibly more important issue is "How much difference does a lower score in these examinations really make?" and "Is this magnitude really meaningful in the admissions process?" This was partially addressed by the Survey of Predoctoral Dental Educational Institutions Volume 1, the most recent results of which were published by the American Dental Association (ADA) in the 2000/01 Survey of Predoctoral Educational Institutions Tuition and Admission, Volume 2. ${ }^{26}$ 
The ADA data indicate that Quantitative Reasoning, the greatest deficit in the DAT for women, is used by fewer schools than any other DAT measure (forty-five of fifty-four schools). All other measures are used by forty-nine or more schools, with the Academic Average used by fifty-three of fifty-four schools. When further explored, the ADA data showed that Academic Average had the highest median weight of 9 followed by Perceptual Ability and Total Science at 7. Reading Comprehension and Biology were at 6 , and both Chemistry scores at 4 . Quantitative Reasoning was lowest at 2. These scores are considered by admissions committees along with other high ranking factors such as science GPA, general GPA, the interview, and recommendations, all of which tend to reduce cultural biasing. ${ }^{25}$ So, it appears that the Academic Average, PAT, and Total Science have the heaviest weighting, but only one, the PAT, is significantly lower for women and accounts for a large percentage score difference between genders. Reading Comprehension, in which women excel, is in the third tier of weighting along with Biology, which showed no differences. The most significant percentage difference between genders was for the least weighted category, Quantitative Reasoning. On the other hand, female students could be jeopardized if schools attempt to aid the admission process by developing algorithms that attempt to predict dental school performance. This is especially true when these algorithms include DAT components that systematically penalize women. In fact, some schools do use this type of methodology.

We found that there were no significant differences between men and women for NBDE I scores. This may be because no true differences exist or because the power of the sample was not sufficient to detect such small differences. NBDE II score results showed a significant difference between men and women. The magnitude at 1 percent is probably not a practical quantitative difference for decision making for two reasons. First, most likely this score would come into play when students are applying to and being considered for graduate programs and residencies in dental specialties. An average difference of one point on the NBDE II is largely irrelevant when considered in conjunction with the host of other information being weighed in the admissions process. Second, the results of these tests are usually not available for students who apply in the autumn of the final year of dental school. For these students, accep- tance decisions are made before the results are released. These scores may come into play for students who apply for advanced training after graduation, but the magnitude of the differences in scores between men and women is too small to be meaningful.

The pass rate on the NBDE I and II and NERB revealed no significant differences although the NBDE II did approach statistical significance $(p=0.065)$. Some would argue that investigating factors that influence passing these examinations is irrelevant because ultimately nearly all candidates pass dental credentialing and licensure examination in one or two attempts. Gender related to licensure passing success has not been examined frequently, but Casada, Cailleteau, and Seals ${ }^{14}$ did not find it to be a significant contributing variable in their investigation of factors that predict dental board licensure performance. Data from the current study confirm these findings for all types of board examinations.

\section{Conclusions}

One would expect equally prepared students of both genders to perform similarly across the complete sequence of high-stakes examinations in dental education when academic performance was controlled. However, we found that small but statistically significant gender differences did exist in DAT and NBDE II scores. These differences between men and women become largely irrelevant at the time of postgraduate admission and licensing due to the small magnitude of the differences in the scores and the fact that passing, not the scores, is the critical measure for the NBDE I and II and regional licensure examinations.

So, do high-stakes gender differences exist in dental professional examinations? It appears that they do exist to some extent, probably for the reasons cited in the educational literature. They may even be reinforced by some aspects of the teaching and evaluation techniques used in dental schools. Are these forces adversely shaping dentistry? If they are, it is at the admissions level where idiosyncratic weighting of DAT scores may take place. Nevertheless, given the consistent increase in women as a percentage of first-year enrollments, ${ }^{27}$ this influence has not prohibited but only possibly slowed the rate of women entering dentistry. 


\section{REFERENCES}

1. Linn MC. Gender differences in educational achievement. In: Sex equity in educational opportunity, achievement and testing: proceedings of the 1991 ETS Invitational Conference. Princeton, NJ: Educational Testing Service, 1992:11-50.

2. Feingold A. Cognitive gender differences are disappearing. Am Psychol 1988;43:95-103.

3. Halpern DF. The disappearance of cognitive gender difference: what you see depends on where you look. Am Psychol 1989;44:1156-8.

4. Gender bias in college admissions tests: gender gap grows again. Cambridge, MA: FairTest: The National Center for Fair \& Open Testing, 2002. At: www.fairtest.org/facts/ genderbias.htm. Accessed: October 19, 2002.

5. MCAT summary data on the combined April/August 2000, 2001, and 2002. Washington, DC: American Association of Medical Colleges, 2002. At: www.aamc.org/students/mcat/ examineedata/pubs.htm. Accessed: November 18, 2002.

6. Coley RJ. Differences in the gender gap: comparisons across racial/ethnic groups in education and work. Princeton, NJ: Policy Information Report, Research Division, Policy Information Center, Educational Testing Service, 2001. At: www.ets.org/research/pic/gender.pdf. Accessed: November 19, 2002.

7. Graham JW. Comparison of males and females in the dental admissions testing program. J Dent Educ 1976;40:783-6.

8. Potter RH. Application of a structural relationship model to gender-related student performance. J Dent Educ 1986;50:549-52.

9. Report of the Council on Dental Education and Licensure, Committee F. Chicago: American Dental Association, 2000.

10. McCreary CP, Gershen JA. Changes in personality among male and female dental graduates. J Dent Educ 1982;46:279-83.

11. Jasinevicious TR, Bernard H, Schuttenberg EM. Application of the diligence inventory in dental education. $\mathrm{J}$ Dent Educ 1998;62:294-301.

12. Smith SA, Rippey RM. Confidence in test taking: a comparison of health profession students by sex and professional school. J Am Med Womens Assoc 1979;34:335-43.

13. Kass SJ, Ahlers RH, Dugger M. Eliminating gender differences through practice in an applied visual spatial task. Hum Perform 1998;11:337-49.
14. Casada JP, Cailleteau JG, Seals ML. Predicting performance on a dental board licensure examination. J Dent Educ 1996;60:775-7.

15. Weinberg E, Rooney JF. The academic performance of women students in medical school. J Med Educ 1973;48:240-7.

16. Case SM, Becker DF, Swanson DB. Performances of men and women on NBME Part I and Part II: the more things change. Acad Med 1993;68(Oct. suppl):S25-S27.

17. Shen L. Gender effects on student performance on the NBOME, Part I, Part II, and Part III. Acad Med 1994;69(Oct. suppl):S75-S77.

18. Norcini JJ, Fletcher SW, Quimby BB, Shea JA. Performance of women candidates on the American Board of Internal Medicine Certifying Examination, 1973-1982. Ann Intern Med 1985;102:115-8.

19. Klein SP. An analysis of the relationship between bar examination scores and an applicant's law school, admissions test scores, grades, sex, and racial/ethnic group. Bar Examiner, 1980.

20. Ryman AE. Women and the bar exam: thinking like a woman lawyer. Drake Law Review 1987/88;37:79-82.

21. Betz NE. Part III contemporary ethical and professional issues in testing and assessment. In: Watkins CE, Campbell VL, eds. Counseling practice vocational psychology, $2^{\text {nd }}$ ed. Mahwah, NJ: Erlbaum Associates, 2000:495.

22. Kidder WC. Portia denied: unmasking gender bias on the LSAT and its relationship to racial diversity in legal education. Yale J Law and Feminism 2000;12:1-42.

23. Maccoby EE, Jacklin CN. The psychology of sex differences. Stanford: Stanford University Press, 1974.

24. Hyde JS. How large are cognitive differences? A metaanalysis using $\mathrm{T}^{2}$ and d. Am Psychol 1981;36:892-901.

25. Sackett PR, Schmitt N, Ellingson JE, Kabin MB. High stakes testing in employment credentialing, and higher education: prospects in a post-affirmative action world. Am Psychol 2001;56:302-18.

26. Survey of predoctoral dental educational institutions, vol. 1; ADA 2000/01 survey of predoctoral educational institutions tuition and admission, vol. 2. Chicago: American Dental Association, 2001.

27. Valachovic RW, ed. Trends in dental education 2000: the past, present, and future of the profession and the people it serves. Washington, DC: American Association of Dental Schools, 2000. 